\title{
Trabajo y vida indígenas en los trapiches del Nuevo Reino de Granada, 1576 - 1674!
}

\section{Gregorio Saldarriaga E. ${ }^{2}$}

RESUMEN: La mano de obra indígena estaba prohibida dentro de los trapiches e ingenios de azúcar por mandato de la Corona española. Sin embargo, en el Nuevo Reino de Granada los oficiales reales, especialmente los corregidores, evitaron ejercer drásticamente esta prohibición y permitieron que muchos indios de encomienda pagaran su tributación con el trabajo azucarero. En este artículo se estudian las razones de esta permisividad, así como los cambios que generó entre los indígenas trabajar en los trapiches, especialmente los aspectos vinculados a la vida comunitaria y a los hábitos de consumo de los indígenas.

PALABRAS-CLAVE: Historia del consumo. Trabajo indígena. Azúcar. Encomienda.

ABSTRACT: By a Crown's rule, native workforce was forbidden inside the trapiches and sugar mills. Nonetheless, some Crown's employees of the New Kingdom of Granada, in particular chief magistrates, avoided exerting this prohibition drastically, and allowed many indigenous people of encomiendas to pay their tributes with their labor on sugar production. This article studies both the reasons of this permissiveness and the changes that working on the trapiches generated among natives, especially those aspects linked to their community life and their consumption habits.

KEYWORDS: History of Consumption. Indigenous work. Sugar. Encomienda.
1. Este artículo forma parte del proyecto (HAR2014-53797-P) Globalización Ibérica: Redes entre Asia y Europa y los Cambios en las Pautas de Consumo en Latinoamérica, financiado por el Ministerio de Economía y Competitividad (España). La investiga-ción y redacción de este artículo fue posible gracias al tiempo que la Facultad de Ciencias Sociales y Humanas de la Universidad de Antioquia me concedió. Agradezco a mis colegas del grupo de Investigación en Historia Social por sus comentarios, críticas y sugerencias, que me ayudaron a refinar la argumentación y enfoque. Igualmente agradezco a Adriana Fontán García por la lectura atenta y paciente, así como por la cuidada corrección de este texto.

2. Profesor Titular del Departamento de Historia de la Universidad de Antioquia. Grupo de Investigación en Historia Social. E-mail: <gregorio.saldarriaga@ udea.edu.co $>$. 
3. Mintz (1999, p. 78).

4. Huetz de Lemps (1996).

5. Mintz (1999), Ebert (2008), Schwartz (2004).

6. Martínez Moya (2011), Moreno Fraginals (2001), Ortiz (1983), Tadman (2000).

7. Funez Monzote (2004 /2009), Miller (1994).

8. En este sentido, me acerco más a los trabajos que han estudiado las zonas que producían derivados de la caña para el autoconsumo, como por ejemplo Barret (1970) para la Nueva España y Sánchez Mejía (2016) para la gobernación de Santa Marta, en el Nuevo Reino de Granada.
Introducción

La llegada de la caña dulce a América y de la industria relativa a su transformación en azúcar o productos derivados transformó paisajes productivos en vastas regiones del continente, pues se dedicaron tierras, aguas y mano de obra a esta empresa tan rentable y tan agotadora de unas y otra. A la par, se transformaron las prácticas de consumo del mundo occidental, porque la abundante disponibilidad de azúcar a partir del siglo XVI hizo disminuir el costo, lo que la hizo cada vez más asequible y más presente en la dieta. ${ }^{3}$ Esta presencia ocasionó, entre otras cosas, que el azúcar remplazara la miel como endulzante principal y que, de a poco, el azúcar dejara de considerarse un producto medicinal para volverse un componente cotidiano de la alimentación de todos los grupos de la sociedad. ${ }^{4}$

La historiografía sobre la producción azucarera es abundante y cuenta con una larga tradición. Se pueden identificar tres grandes líneas de trabajo: 1) la forma en que ciertas partes de América se dedicaron a la producción azucarera y se vincularon comercialmente con países europeos. En estos casos prevalecen los estudios sobre Brasil y las Antillas; ${ }^{5}$ 2) los efectos de la producción azucarera en la economía y demografía de América, en especial de las Antillas, con la introducción de la mano de obra esclava proveniente de África; 6 3) los efectos ecológicos de la producción azucarera. ${ }^{7}$ El grueso de los trabajos en estas líneas son muy buenos y han permitido conocer el mundo de los ingenios y del gran comercio de azúcar, en donde se daba la mayor cantidad de producción de azúcar en los momentos que estudia.

En este artículo me aparto de estas perspectivas, porque me concentro en una zona de producción azucarera periférica, el Nuevo Reino de Granada, ${ }^{8}$ para entender de qué manera se integraron los grupos indígenas tanto al cultivo de caña como a su transformación en diversos tipos de derivados entre finales del siglo XVI y finales del XVII. Es una zona periférica en tanto no tuvo una conexión notable con el comercio exterior, sino que su producción estuvo dirigida a abastecer la demanda interna por estos productos. Además de eso, al estudiar las zonas de producción en que la mano de obra principal era aportada por indígenas y no por africanos esclavizados, se prestará atención a los sitios en que la producción de azúcar y dulces era más limitada aun. A pesar de sus alcances limitados en producción y en incidencia en un nivel internacional, permiten entender cómo se presentaron experiencias laborales y de consumo que no estuvieron mediadas por los grandes ingenios.

La integración de los indígenas en el trabajo azucarero en el Nuevo Reino de Granada se dio bajo dos circunstancias: la primera, la prohibición de la Corona del trabajo de los indios en los procesos productivos dentro de los ingenios; la segunda, la mayor frecuencia de trabajo indígena en trapiches que en ingenios, con una producción más modesta que los ingenios, donde la mano de obra mayoritaria era de origen africano. Según el Tesoro de la lengua castellana o 
española, un trapiche es un ingenio de azúcar; ${ }^{9}$ aunque había diferencias entre uno y otro, que residían en la fuerza de tracción, el tamaño, el valor y la capacidad de producción. En el ingenio, el agua movía la molienda; en el trapiche, la fuerza animal. ${ }^{10}$ El ingenio valía en el siglo XVI, según las estimaciones del comerciante florentino Galeotto Cey, tres veces más que el trapiche y en esta misma proporción producía ganancias. ${ }^{11}$ Por lo tanto, el nivel de inversión y de especialización en el ingenio permitía que produjeran mucho y, sobre todo, que alcanzaran a hacer, mediante la contratación de personal especializado (maestros azucareros), el producto más refinado de toda la operación: el azúcar blanco. Si bien en los trapiches en los que trabajaron los indígenas había una inversión importante en infraestructura, parecía más bien una actividad económica complementaria a las que tenía el encomendero o una forma de aprovechar la mano de obra de su encomienda. También hubo casos en los que los indígenas eran los dueños de trapiches, pero pequeños. Tanto en los que pertenecían a encomenderos como a indígenas primaban azúcares oscuros no sometidos a la "purga", mieles de caña y conservas de frutas que se empacaban en cajetas de madera. Estos productos no alcanzaban el precio del azúcar blanco, pero no por eso dejaban de tener un mercado importante en ciudades y minas. ${ }^{12}$

Para entender cómo se dio esta integración de los indígenas, se tomará en cuenta tanto la obligación que se les imponía como la apropiación de los pueblos de la producción del dulce en términos laborales, de sociabilidad len términos comunitarios o interétnicos) y de consumo de los productos que se preparaban en los trapiches.

Prohibición de trabajo indígena en labores azucareras

Uno de los marcos de referencia de este trabajo está dado por la prohibición que existía para que los indios trabajaran en los ingenios. La primera que hemos encontrado data de $1576 .{ }^{13}$ En ella se indicaba que, por la necesidad de proveerse de azúcar, miel y vinagre, se autorizaba, en las encomiendas con suficientes indígenas para doctrinar, que el encomendero les pagara para que le cultivaran una cuadra de 75 varas de caña dulce y se encargaran de toda la faena agrícola, que incluía llevar las cañas hasta el trapiche. Explícitamente se prohibía su trabajo dentro del trapiche, así como en las faenas posteriores: proveer múcuras (vasijas de barro) para contener los derivados de la caña o transportar los derivados a los mercados. ${ }^{14}$ En ese momento se asumió como norma que el trabajo en los ingenios debía ser realizado por negros y delimitaba el trabajo indígena a un aspecto puntual: la faena agrícola. Esta ordenanza era para una región en particular (Tunja y sus términos), pero correspondía con una idea general: el azúcar era fundamental para la sociedad colonial, pero el trabajo en los ingenios afectaba la vida de los indígenas. Tal vez el hecho de abrirse la ventana de la necesidad hizo que estas normas no se cumplieran estrictamente, no solo las relativas al
9. Covarrubias (1611), f. 52r.

10. Rodríguez Morel (2004, p. 97-98), Martínez Moya (2011, p. 41)

11. Cei (1992).

12. Según las autoridades de Tunja, la arroba de azúcar costaba dos pesos, en tanto que la arroba de conservas (guayaba, naranjas y turrón) peso y medio, pero la de diacitrón, es decir cidra, tres pesos, así como la botija perulera de conserva de limones. En ese caso, lo más probable es que se trate de azúcar morena. "Descripción de la ciudad de Tunja, sacada de las informaciones hechas por la Justicia de aquella ciudad en 30 de mayo de 1610" (Colección de documentos inéditos, 1964, volumen 9, p. 427)

13. Para la Nueva España, dicha prohibición se estableció desde la década de 1540. Schwartz (2004, p. 12). Aunque según Barret (1970, p. 80), la orden en la Nueva España solo se hizo efectiva a finales del siglo XVI.

14. Archivo General de Indias (AGI), Patronato, 196, r. 8. f. $10 \mathrm{v}$. 
15. "Que los indios no sirvan en obrages, ni ingenios de azúcar" (Recopilación, 1791, libro VI, título XIII, ley VIII, p. 301). Valga la pena señalar que en este apartado se equiparaba la prohibición de que los indios trabajaran en ingenios azucareros y en obrajes de telas.

16. AGI, Santa Fe, 99, n. 3, "Carta de Juan de Unda Jáuregui, 8 de mayo de 1609".

17. Recopilación (1791, libro VI, título XIII, ley XI, p. 302).

18. Konetzke (1958), documento 508, p. 753: "R. C. al gobernador de Caracas guarde la ley que prohibe que los indios trabajen en trapiches, ni ingenios de azúcar".

19. Para un estudio sobre el trabajo indígena y sus condiciones de vida, véase Bonnett (2009).

20. Cuando se trataba de ingenios, se debía tener varios cultivos al mismo tiempo, para garantizar mayor producción. trabajo dentro del ingenio, sino también a las del transporte de los productos y la provisión de contenedores para los derivados de la caña, que no fueron múcuras de barro, sino cajetas de madera.

Esta prohibición se repitió por lo menos dos veces más en poco tiempo, en 1595 y en 1601 . Según la Recopilación de las Leyes de Indias, además de establecer la interdicción del trabajo indígena forzado o concertado en los ingenios y "trapiches de azúcar", se establecían los castigos para los particulares que los pusieran a trabajar en esta actividad, así como para los oficiales reales y jueces que lo permitieran. ${ }^{15}$ Ocho años después de la última prohibición, Juan Ochoa de Unda Jáuregui, como corregidor de Tunja, solicitó que se levantara para los obrajes y para los trapiches, porque, según él, "generalmente privar del regalo que ofrecen cosas dulces donde tan poco hay y de azúcar para la salud y medicina tiene con licencia de VM muy grande inconveniente". ${ }^{16}$

Esta solicitud es llamativa, porque parece señalar que faltan cosas dulces, pero sobre todo que Tunja y muy probablemente el Nuevo Reino de Granada en general carecían de regalo, es decir, de elementos que hicieran gozosa la vida. Por lo tanto, aunado a la necesidad que la salud y la medicina tenían del azúcar, era vital que los indígenas pudieran trabajar en los ingenios o trapiches de puertas para adentro. No obstante estos argumentos, la Corona no solo denegó esta solicitud sino que reiteró la prohibición otras dos veces. A comienzos del siglo XVII, durante el reinado de Felipe III, se ratificó que los indígenas no podían trabajar ni siquiera voluntariamente en los ingenios de azúcar de españoles; de nuevo, su única actividad en el proceso de producción azucarera se restringiría a las tareas agrícolas. ${ }^{17}$ En 1683, se reiteró la prohibición por medio de una Real Cédula dirigida al territorio de Caracas. Aunque este territorio no pertenecía a la Audiencia del Nuevo Reino de Granada, es interesante porque señala que, si bien no hay ingenios ni obrajes, "hay sin embargo unos que llaman trapiches, en que se miele el melado", a los que se extiende la prohibición del trabajo indígena por los inconvenientes que representaban para la vida indígena. ${ }^{18}$

Lo que se permitía a los indígenas, e incluso se esperaba de ellos como ya se mencionó, era que hicieran el trabajo agrícola vinculado a la producción azucarera. ${ }^{19}$ El área cultivada variaba de acuerdo a la capacidad de producción del trapiche. Es importante tener en cuenta que la caña dulce es un cultivo de crecimiento más o menos lento, pues, en clima cálido, no está lista para exprimirla hasta el segundo año después de sembrada y, en clima frío, hasta el tercer o cuarto año. Por lo tanto, para garantizar una producción anual, era necesario tener más de una sementera cultivada en un sistema intercalado. ${ }^{20}$ Como era parte del tributo, en algunas regiones el encomendero se encargaba de que los bueyes araran la tierra - bien porque contrataba el trabajo o porque ponía los bueyes y el arado a disposición de la comunidad - y cada pueblo hacía el cultivo. Como el maíz era omnipresente en buena parte de las obligaciones tributarias, en ocasiones se sembraba intercalado con la caña en la misma área de cultivo. Con la siembra no 
cesaban los trabajos, porque debían desyerbar el terreno una o dos veces al año para que el cultivo de caña prosperara. Cuando estaba lista para la recolección, debían cortarla de tal manera que permaneciera la soca, es decir, la base y la raíz de la planta. Así crecía nuevamente y se producía la segunda cosecha de un mismo cultivo, que tardaba otros dos años en volver a estar lista para su explotación. Después de esto, se debía comenzar el proceso de cultivo nuevamente por medio de la repoda, porque ya no produciría más después del segundo corte. ${ }^{21}$

Este sistema de trabajo agrícola no era en modo alguno indígena, salvo por la forma de entremezclar el maíz con la caña, como se hacía con los frisoles o con la yuca; más bien debió de ser un modelo de trabajo aprendido de los españoles, que también se usaba en los ingenios en que no trabajaban indios de encomienda. Así pues, esta labor agrícola no es interesante por ser excesivamente singular, sino por las variantes que adquiere al introducirse entre los indígenas que tributaban. Como se sabe, el tributo era una obligación impuesta a los hombres adultos (aproximadamente entre 17 y 50 años); estaban exentos los caciques y capitanes de cada pueblo, las mujeres, los niños y los viejos. Sin embargo, este principio de cobro se incumplió sistemáticamente, en parte por la forma en que los encomenderos entendían que la encomienda les pertenecía como un todo, incluyendo a las personas y su trabajo, pero también por las características colectivas que el trabajo agrícola tenía para estos grupos humanos: era común que todos participaran en las faenas del campo, según sus posibilidades y su posición social. Este trabajo comunitario que se daba en las actividades tradicionales (p.e. cultivo de maíz y yuca, y caza de manatíes), también se integró al trabajo con la caña dulce. Se puede ver cómo las mujeres trabajaban en su cultivo, desyerbe, corte o traslado hasta los trapiches, en ocasiones como fuerza de trabajo complementaria - hombro a hombro con los hombres-, o bien encargadas de toda una actividad, mientras los hombres se encargaban de otra como, por ejemplo, las labores propias de la preparación de la caña dentro del trapiche. 22 Por lo tanto, la comunidad estaba involucrada de manera global en el proceso productivo, en parte porque era necesario hacerlo de manera intensiva en el menor tiempo - para evitar pérdidas en la cosecha-, en parte para liberar a los hombres de estas obligaciones lo más pronto posible para que estos pudieran desempeñarse en sus propias parcelas, donde sembraban sus productos de consumo o venta.

Además de esto, había por lo menos tres actividades más de los indígenas que eran fundamentales para el funcionamiento de los trapiches. Primera, la construcción y mantenimiento del trapiche. ${ }^{23}$ Si bien esta no era una actividad regular, demandaba cierto trabajo. Además de las reparaciones que necesitaban, en ocasiones se incendiaban y había que reponerlos completamente. Asimismo, como los trapiches no requerían la inversión de un ingenio, en ocasiones sus dueños decidían moverlos de sitio para, por ejemplo, acercarlos a nuevas zonas de cultivo de la caña. Segunda, el transporte de grandes cantidades de leña a los trapiches
21. En algunas regiones, especialmente cálidas, se podía hacer incluso la resoca, que era volver a hacer el corte, pero dejando la base de la caña, para que creciera nuevamente, Ramírez Méndez (2014, p. 17). Para una descripción detallada del proceso agrícola con la caña, pero también del trabajo y de las herramientas utilizadas en su transformación, véase Ximénez (1615). Aunque fue escrito sobre la Nueva España y las Antillas, describe bien el modelo general. Es preciso señalar que siempre está pensando en ingenios y nunca menciona los trapiches.

22. AGN, Colonia, Visitas de Antioquia, t. 3, d. 6, f. 842v; Visitas de Boyacá, t. 1, d. 6, f. $737 \mathrm{v}$; Visitas de Cauca, $t$. 1, d. 4, f. $917 \mathrm{v}$.

23. AGN, Colonia, Visitas de Boyacá, t. 1, d. 6, f. 732v. 
24. Para el caso del transporte de leña a las ciudades por parte de los indígenas, véase Vargas Lesmes (1990) y Vanegas Durán (2015).

25. AGN, Colonia, Visitas de Boyacá, tomo 1, d. 6 , f. 732 r.

26. Para observar algunas representaciones de los tipos de ingenios o trapiches que había en América, al tiempo que un análisis sumamente sugerente de las imágenes en las que se representaron, véase Crowley (2016).

27. AGN, Colonia, Visitas de Santander, t. 7, d. 4, f. 490r.

28. AGN, Colonia, Visitas de Boyacá, t. 2, d. 6, f. 735r. para cocer los jugos que se extraían de las cañas para convertirlos en miel, azúcares o conservas, o bien para hornear los panes de azúcar. ${ }^{24}$ Tercera, la provisión de alimento a los que trabajaban dentro del trapiches, especialmente si eran esclavos especializados en estas tareas. ${ }^{25}$ Sin unas y otras actividades era imposible el funcionamiento de estos sitios de producción. En parte por eso, la Corona promovió que las comunidades las realizaran como parte de su tributo, aunque también por medio del concierto, es decir, el contrato.

El trabajo en el trapiche

Como señalé previamente, a pesar de las prohibiciones existentes, también se utilizaron a los indígenas en labores internas de los trapiches y en algún ingenio que funcionó con indios, como por ejemplo en la encomienda de Berigua. Asimismo anoté que la diferencia entre ingenio y trapiche estaba dada por el tamaño del establecimiento, el volumen de la producción y el tipo de fuerza de tracción. En tanto que el ingenio era hidráulico, en el trapiche se movían las moliendas con la fuerza de un animal, mula o caballo; en ocasiones, ante la falta del equino, diez o doce hombres se encargaban de la tarea; también existían trapiches de "manos", diseñados para que la fuerza la ejercieran los brazos de una o pocas personas. Estos trapiches manuales estaban muy extendidos a comienzos del siglo XVII en el occidente del Nuevo Reino de Granada, en las encomiendas que estaban al norte de la gobernación de Popayán. ${ }^{26}$ El tamaño de los trapiches era variable; había unos que incluso contaban con espacios divididos para la molienda y para la casa de purga. Había otros que tenían horno para los panes de azúcar y otros que simplemente llegaban hasta la cocción de la miel y la preparación de conservas.

En los trapiches más grandes era usual un mayor número de empleados y también un trabajo más especializado. Así, en el ingenio de la encomienda de Berigua, había indígenas que trabajaban como parte de su tributo en las siguientes actividades: cuatro en moler la caña para sacar los primeros jugos; seis en prensarla y terminar de extraer los jugos restantes, y tres en cocerlos - espumadores - en pailas de cobre. Además de eso, había dos morenos que se encargaban de la leña (uno la cortaba y otro prendía el fuego y lo alimentaba) y un negro esclavo que se encargaba de la elaboración del azúcar. ${ }^{27}$

En los trapiches, las personas dedicadas a la molienda se dedicaban también a la prensada; es decir, que los mismos que pasaban la caña por la tahona o molino se encargaban de ponerlo en la caja para el prensado. ${ }^{28}$ En algunos se daba cuenta de la presencia de jóvenes indígenas encargados de retirar el bagazo y acomodarlo para que, posteriormente, cuando estuviera seco, sirviera de leña. En los trapiches de tracción animal, alguien debía arrear el animal que accionaba el molino. Otra función fundamental en el proceso era la de hornero, el encargado de asegurar que los panes de azúcar quedaran bien cocidos y listos 
para hacer la purga de la que se obtenía el azúcar blanco. Sin embargo, lo común en los trapiches en los que trabajaban indígenas es que no se hiciera el proceso de purga, por falta de un maestro azucarero. Asimismo es preciso señalar que no en todos los trapiches había hornero, porque en muchos de ellos no se llegaba a elaborar panes de azúcar, solo mieles de caña y conservas. Por ejemplo, en los trapiches manuales o de "rueda de manos", por sus dimensiones limitadas, solo se sacaba un poco de miel; en ellos, entre dos y cuatro personas podían hacer el trabajo de la molienda: meter la caña, retirar el bagazo, hacer la fuerza de la tracción y luego cocer los jugos en las pailas. Toda la labor se terminaba en uno o dos días de intenso trabajo, pero no se sacaban más que unas cuantas botijas de miel. ${ }^{29}$

Había, además, dos oficios externos vinculados al trapiche, que también desempeñaban los indígenas, a pesar de estar vedados para ellos: cajeteros (quienes fabricaban las cajetas de madera en que se empacaban las conservas) y cargueros (quienes llevaban los productos con animales de carga desde el trapiche hasta las ciudades, mercados o minas donde se vendían).

Progresivamente, algunos indios se fueron especializando en alguna de las actividades y manifestaban encontrarse a gusto en ella, como Antón Cuchanchipa, espumador y uno de los 10 indios concertados que don Luis Cabeza de Vaca tenía trabajando en su trapiche cerca de Tenza en 1621. La especialidad no daba para que fuera su única actividad, porque el trabajo en el trapiche era muy intenso pero relativamente corto (de pocos días hasta cuatro meses). Por esto, Antón era espumador durante el proceso con la caña, y seguramente dedicaba el resto del tiempo a actividades agrícolas. A cambio de su trabajo en el trapiche no recibía un pago en metálico, sino una mezcla de bienes y conmutación de sus obligaciones como encomendado. Así, el encomendero no le cobraba tributo a Antón en el año y además cubría su parte de lo que correspondía a la Corona y al pago anual para el corregidor. A pesar de que la conmutación estaba explícitamente prohibida, se presentaba frecuentemente como una forma de negociación entre el encomendero y sus tributarios, bien fuera cambiando unos productos por otros o bien por servicios personales, como en este caso. ${ }^{30}$ Por su trabajo, Antón recibía, además, la comida durante el tiempo que laboraba en el trapiche, una camiseta o sayal, una manta de lana, un potro cada dos años y una o dos botijas de miel de caña en cada etapa de producción. ${ }^{31}$ En otros pueblos en donde había trapiche se siguió una lógica similar: conmutar el tributo por alguno de los trabajos de la molienda y, en ocasiones, agregar incentivos que hicieran atractivas estas actividades para los indígenas. Lo más frecuente era la simple conmutación del tributo, como por ejemplo en Moniquirá, donde, en 1642, el encomendero hacía trabajar a los indios en el trapiche sin pagarles nada, pero tampoco le cobraba a cada uno el tributo de cinco pesos y dos gallinas al año. Solo les pagaba una camisa de lana al año a los indígenas que ya no tenían que tributar. ${ }^{32}$
29. AGN, Colonia, Visitas de Cauca, t. 4 , d. 17 , f. 958 v.

30. Para un análisis del proceso de la conmutación como negociación, véase Gamboa Mendoza (2010).

31. AGN, Colonia, Visitas de Boyacá, t. 15, d. 3, ff. 218 r y v.

32. AGN, Colonia, Visitas de Boyacá, t. 13, d. 5, ff. $719 \mathrm{v}$ y 722 r. 
33. Gómez Gómez (2015).

34. Para el caso brasilero, Schwartz plantea que había una distancia entre el trabajo especializado y el trabajo esclavo, pues este último no era altamente especializado y era intercambiable entre los esclavos que trabajaban en la plantación (2004, p. 3).

35. AGN, Colonia, Visitas de Boyacá, t. 1, d. 6, f. 737v; Visitas de Cundinamarca, t. 6, d. 5, f. 672v; Visitas de Santander, t. 3, d. 2, f. 360r; t. 4 , d. 2 , f. $318 \mathrm{r}$
La especialización artesanal no parece haber generado suficiente impacto como para alejar a molineros, espumeros y horneros de los pueblos en busca de nuevas alternativas laborales por fuera de la encomienda, como sí pasó con otros tipos de trabajos artesanales como, por ejemplo, el de sastrería. ${ }^{33}$ Tal vez algunos de los indios que trabajaban en los trapiches se fueron del pueblo, pero nadie vinculó estas huidas directamente con su actividad en el trapiche. A falta de información sobre el trabajo de indígenas en algunos ingenios como asalariados no encomendados, considero que lo que dificultaba su movilidad laboral con tareas especializadas era que ellos no se dedicaban a la más estimada de todas: la purga del azúcar. Las otras funciones, si bien implicaban cierto grado de destreza, se aprendían con poco entrenamiento; por esta razón, era muy fácil destinar a alguien a ellas, sin necesidad de recurrir al mercado laboral. ${ }^{34}$

Lo anterior nos permite entender que los trapiches no implicaban el extrañamiento de la comunidad para los indígenas que trabajaban en ellos. Por el contrario, su trabajo tenía características comunitarias. Al igual que se vio con la parte agrícola, también de puertas para adentro, mujeres y muchachos participaban de las labores, en ocasiones sin dejar testimonio de la diferenciación de actividades entre ellos; en otras, explicitaron que los muchachos se encargaban de retirar el bagazo, en tanto que las mujeres eran espumadoras; en otras, que había jóvenes y mujeres trabajando con esclavos, compartiendo actividades en la preparación de conservas. ${ }^{35}$ Quienes no tenían que pagar tributo (mujeres y jóvenes) se dedicaban a estos trabajos por razones homólogas a las de colaboración en el cultivo: entre menos tiempo dedicaran los hombres al trabajo en el trapiche, más pronto podían dedicarse todos juntos a las actividades de sustento del pueblo; esto se lograba cuando todos apuraban algunas de las labores del trapiche trabajando día y noche. Otra razón para participar en este trabajo era que recibían pago cuando lo hacían conjuntamente con negros, lo que les permitiría acceder a cosas que por otra vía resultaban costosas de comprar, como camisas o telas.

Durante del periodo comprendido, como ya se ha mencionado, en términos generales, los trapiches trabajados por indios de las encomiendas se organizaban en torno al trabajo comunitario. Esto no significaba que todos los miembros del pueblo participaran, sino que se trataba de aprovechar el trabajo de sus diversos miembros, en un sistema casi familiar. La mejor muestra de esto se puede encontrar en la encomienda de Boquipi, términos de Muzo, de donde, alrededor de 1611, el encomendero Alonso Jiménez sacó a doce tributarios con sus familias y las llevó a quince kilómetros de su pueblo para asentarlos en Tapachicpi y ponerlos a trabajar integralmente en las labores de la producción de dulces, desde el cultivo y cuidado de la caña -amén de otras actividades agrícolas - hasta las labores en el trapiche. Estos doce hombres y sus familias se constituyeron en una unidad de producción extrañada de su pueblo, pero constituida en sí misma en comunidad. El encomendero no pretendió fomentar una especialización que garantizara la movilidad laboral de los indígenas, sino 
que los trasladó de su comunidad para garantizar una dedicación y continuidad de los esfuerzos laborales. ${ }^{36}$

En el caso citado anteriormente, por los testimonios parece que los dos únicos elementos que quedaban faltando para hacer de esta célula de trabajo perfectamente autónoma con respecto a la explotación de la caña eran la fabricación de recipientes para verter las conservas y el transporte de mieles, azúcares y conservas hacia sus destinos de venta. Para entender cómo funcionaban estas dos tareas tenemos los testimonios de otras encomiendas. De todos los envases que se utilizaron para los productos dulces, parece que los indígenas de las encomiendas solo se encargaban de las cajetas de las conservas, porque nunca se mencionan las botijas en que se metían las mieles ni las cajas en que se ponían los panes de azúcar, blancos o morenos. Tal vez las cajas las hacían especialistas por fuera de las encomiendas, porque se buscaban relativamente finas, que pudieran reutilizarse varias veces. Por el contrario, las cajetas de las conservas eran productos perecederos que terminaban su vida útil casi al mismo tiempo que el contenido. Desconozco su tamaño. Por su nombre, se sabe que no eran muy grandes; sin embargo, estimar un diámetro resulta aventurado.

La cantidad de indios dedicados a la fabricación de las cajetas variaba según la capacidad productiva. En ocasiones podían ser solo dos y, en otras, una docena dedicados específicamente a hacerlas. Como en los casos de labor interna del trapiche, se podría hablar de una especialización laboral en la que los indígenas se encargaban de todo el proceso, incluida la selección y corte de los árboles que estaban en los montes cercanos - en ocasiones a una legua -, para obtener la madera necesaria. ${ }^{37}$ Era un trabajo dispendioso dividido en varias etapas, que implicaba cortar los árboles, arrastrarlos con bueyes hasta el sitio en que los convertían en madera trabajable, para después comenzar a hacer las cajetas. Esto, a su vez, tenía sus propias complicaciones: debían hacerlas de manera intensiva, inmediatamente antes y durante el tiempo que se realizaba la preparación de las conservas; si las hacían con mucha antelación, se presentaban dificultades para almacenarlas y para conservarlas sin que se dañaran. Según el testimonio de los indios de Gachantivá, ellos empleaban cuatro meses al año haciendo las cajetas junto al trapiche, que estaba a treinta y cinco kilómetros de sus casas. Durante este tiempo, el encomendero y sus hijos los presionaban para que cada uno hiciera doce cajetas al día, pagándoles poco o nada a cambio y sin proveer las herramientas necesarias para esa tarea. ${ }^{38}$ Estos cuatro meses de trabajo eran extenuantes para los indígenas, porque la cantidad diaria pedida era muy alta, razón por la que ponían a sus hijos a trabajar con ellos. De nuevo vemos este mecanismo de ayuda de los miembros no tributarios a los que sí lo eran para poder cumplir con sus obligaciones ante el encomendero. ${ }^{39}$ Por supuesto, los indios encontraban estas cargas excesivas para ellos. Además se quejaban de que tanto tiempo alejados de su pueblo los perjudicaba, al no poder proteger sus pertenencias ni hacer sus cultivos para su autoabastecimiento. Es decir, con la labor de cajeteros no se cumplía la premisa de que los indios debían entregar solo un excedente de
36. AGN, Colonia, Visitas de Boyacá, t. 16, d. 2, f. $344 \mathrm{v}$.

37. AGN, Colonia, Visitas de Boyacá, t. 1, d. 6, f. 728 . Desafortunadamente ni a los testigos ni a los visitadores les interesó informar cuáles árboles se preferían para hacer estos contenedores. Según el comerciante florentino Cey (1992), la madera utilizada era la del jobo (Spondias mombin), porque era ligera.

38. AGN, Colonia, Visitas de Santander, t. 2, d. 13, f. 555 r.

39. De manera aproximada, los indios de esta encomienda debían hacer cerca de 13.824 cajetas en esos cuatro meses. 
40. AGN, Colonia, Visitas de Santander, t. 2, d. 13 , f. 556 r.

41. AGN, Colonia, Visitas Boyacá, t. 2, d. 6, ff. 733r, 791v y 799v; Visitas de Boyacá, t. 3, d. 14, f. 840v; Visitas de Cundinamarca, t. 3, d. 2 f. 441r; Visitas de Santander, t. 4, d. 2, f. 318v; Visitas de Santander, t. 6, d. 10, f. $795 \mathrm{v}$

42. AGN, Colonia, Visitas de Santander, tomo 4, d. 2 , f. $318 v$.

43. AGN, Colonia, Visitas de Boyacá, tomo 15, d. 3, f. 235v. su mano de obra, sino que se constituía en un servicio personal que no se concertaba ante el corregidor y que los alejaba de su actividad principal. Incluso se puede entender, por la queja de los indígenas en 1642, que el encomendero se negaba a perder el monopolio de la mano de obra de su encomienda, y por eso los ponía a trabajar tanto como fuera posible, les impedía que alquilaran su mano de obra en Villa de Leiva o que vendieran allí la madera que cortaban. ${ }^{40}$

Portar azúcares, mieles y conservas también implicaba una especie de trabajo especializado, el de los arrieros, que desde los trapiches llevaban las mulas cargadas a los puntos de venta como Honda, Mariquita, Santa Fe, Ocaña, Pamplona, Trinidad de la Palma, Tunja y algunos centros mineros. Tanto el número de arrieros como de mulas dependían de la producción de los trapiches y del tamaño que tuviera la población de destino. Entre los arrieros que se encuentran en el periodo estudiado, se puede ver desde uno con pocas mulas, hasta seis con 40 mulas, aunque predominaba menor número de hombres y de mulas. Muchos de esos arrieros no llevaban solo los productos dulces sobre las mulas, sino también otras mercancías de la encomienda, entre ellas maíz. ${ }^{41}$

La duración del trabajo en el trapiche dependía de la cantidad de caña disponible para moler y de la capacidad instalada en máquinas y mano de obra. Podía durar desde unos pocos días hasta meses. Era un trabajo intenso, de tareas impostergables, porque no podía transcurrir mucho tiempo entre el corte de la caña y la molienda, para no perder calidad ni cantidad en los jugos. Por eso había trapiches con jornadas largas de trabajo, que abarcaban día y noche. ${ }^{42}$

En este ambiente podían presentarse accidentes graves, que implicaban la pérdida de la vida o la amputación de extremidades. Las amputaciones se presentaban al meter las cañas dentro del molino. En un descuido, la mano con que se metía la caña quedaba atrapada por los "dientes"; cuando se lograba detener el accionar, ya buena parte del brazo estaba comprometido y se debía amputar. En las visitas consultadas, no apareció ningún indio amputado por esta causa; solo un esclavo que había sufrido el accidente muy joven, mientras trabajaba con los indígenas. ${ }^{43}$

Uno de los posibles accidentes en el trapiche se producía en las calderas, donde los zumos de caña dulce hervían a altas temperaturas. Los espumadores corrían el peligro de resbalar y caer dentro de ellas. Sin embargo, este tipo de accidente tampoco aparece con frecuencia en la documentación consultada. Solo hay una referencia de un caso ocurrido en la segunda década del siglo XVII, cerca de Tenza. Es un caso interesante, porque en un principio se dice que era un indio concertado que trabajaba en el trapiche de Diego Núñez de Estupiñán. Sin embargo, a medida que se interrogaba a los testigos que trabajaban en el trapiche en donde ocurrió el accidente, se señalaba que era externo al trapiche, pues era un joven (entre 16 y 20 años) que visitaba a su cuñado (Cristóbal Unbagán), que sí trabajaba allí. De esta manera, el encomendero dejaba de ser responsable del accidente. Además de eso, los testigos agregaron que el joven tenía características poco confiables: a Lorenzo lo calificaban de 
insensato y loco, y por estas razones no pagaba demora a su encomendero. El día del accidente:

[...] Este testigo [Juan Negro] estaba espumando la paila y su cuñado del indio tonto fue a traer agua para echar en la paila porque quería ya este testigo sacar el caldo y el dicho indio tonto estaba allí arriba mirando como este testigo espumaba y este testigo se bajó abajo a atizar el horno y entonces como estaba solo arriba el dicho Lorenzo el mismo se echó dentro de la paila en que estaba cociendo la miel y este testigo acudió corriendo a sacarlo y cuando lo sacó ya estaba quemada su carne y llegó allí su cuñado con el agua y luego se murió. ${ }^{44}$

Es preciso señalar que, según los testimonios de Cristóbal y Juan, ellos dos eran los únicos que estaban con Lorenzo el día del accidente y que ninguno lo presenció, porque Juan estaba atizando el fuego y Cristóbal trayendo el agua. Con respecto a la forma en que Lorenzo cayó en la paila, hicieron una composición de lugar, pero no podían saber qué pasó. ¿̇Era un insensato que se tiró al fuego o un desgraciado que se resbaló? Los testimonios de Juan Negro, del cacique y de su propio cuñado pintaban un cuadro poco halagüeño de Lorenzo, achacándole toda la responsabilidad del accidente a su comportamiento y exculpando el trabajo en el trapiche, en el que todos los implicados parecían sentirse cómodos.

La poca presencia de registros de accidentes en el trapiche nos enfrentan a un problema: ¿había tan pocos accidentes laborales? ¿ $\bigcirc$ estamos ante un problema de registro? Se puede pensar que se presentaron los accidentes, pero no quedaron consignados porque los encomenderos presionaban a los indios a no mencionarlos, o bien a ellos no les interesaba hacerlo para preservar un trabajo que les permitía acceder a bienes que de otro modo no eran fáciles de conseguir. Por testimonios de visitas y otra documentación, sabemos que hubo encomenderos que presionaron a los indios para que no se quejaran ante los visitadores, pero no podemos señalar que se hubieran presentado por parte de encomenderos que tuvieran trapiches. Incluso, por el tipo de quejas contra los encomenderos que tenían trapiches, me atrevo a pensar que los accidentes no eran una moneda corriente o bien no lo eran como para llamar la atención de los indígenas. ${ }^{45}$

Sin dejar de lado que nueva evidencia puede aparecer en el futuro, es posible pensar que la especialización del trabajo minimizó los riesgos, porque cada uno aprendía su oficio y los peligros que entrañaba, ${ }^{46} \circ$ bien porque, en el caso del trabajo con el molino, se popularizó el uso de canaletas largas y palos que empujaban las cañas, con lo que se alejaban las manos del peligro de la tracción. ${ }^{47}$

Tal vez el gran peligro que entrañaba el trabajo en el trapiche estaba marcado por los servicios personales, es decir, aquella lógica según la cual el trabajo de los indios pertenecía a los encomenderos y estos podían emplearlos y explotarlos a su libre voluntad. En teoría, con la promulgación de las Leyes Nuevas en 1542, esta posibilidad ya no existía, porque con la imposición de la tributación regulada por los oficiales reales, los indígenas solo debían dar un excedente de su
44. AGN, Colonia, Visitas de Boyacá, t. 15, d. 3, f. 236v.

45. Para un estudio de las relaciones entre indígenas y encomenderos en el periodo estudiado, véase Gómez Gómez (2014, p. 8-26).

46. AGN, Colonia, Visitas de Boyacá, t. 15, d. 3, f. 290r.

47. AGN, Colonia, Visitas de Boyacá, t. 15, d. 3, f. 251v. 
48. Colmenares (1999, p. 131).

49. AGI, Quito 24, n. 38, ff 2v y $3 r$.

50. AGN, Colonia, Visitas de Santander, t. 2, d. 13, f. 522r.

51. AGN, Colonia, Visitas de Boyacá, t. 1, d. 2, f. 148r.

52. Saldarriaga (2011, p. 122-130).

53. AGN, Colonia, Visitas de Boyacá, t. 1, f. 415r; Visitas de Boyacá, t. 15, f. 256r; Visitas de Cundinamarca, $t$. 3, f. 414 r. mano de obra, que podía ser en especie, metálico o incluso en trabajo específico. Por lo menos en el Nuevo Reino de Granada, a partir de 1590, los encomenderos perdieron el monopolio de la mano de obra indígena. A partir de ese momento, solo podían contratar a una parte de los hombres de su encomienda para trabajos específicos, debiendo dejar libres a los otros para que los contrataran personas que necesitaran trabajadores agrícolas, pecuarios o urbanos. El proceso de contratación, ya fuera por el encomendero o por particulares, se debía hacer ante el corregidor, para que este consignara las obligaciones de ambas partes, el salario y la forma en que se había concertado tal trabajo. ${ }^{48}$ Fue la manera en que la Corona buscaba restringir el poder de los encomenderos sobre las poblaciones indígenas. A pesar de estos intentos de regulación, algunos encomenderos mantenían las aspiraciones de explotar las encomiendas por medio de los servicios personales, sin respetar la voluntad o las necesidades de las comunidades indígenas. En el caso específico de los trapiches, este deseo se podía manifestar en el encierro a que se sometía a los indígenas para que se dedicaran exclusivamente a la labor azucarera durante la temporada de trabajo. ${ }^{49} \mathrm{~A}$ esto se le sumaban los excesos de actividades impuestas, la movilización obligatoria lejos de sus pueblos y la forma en que justificaba el encomendero todas estas acciones diciendo públicamente que los indios eran sus negros esclavos. ${ }^{50} \mathrm{Sin}$ duda el caso extremo se presentó en la provincia de Vélez, en el trapiche de Lenguaruco, en donde, para castigar y disciplinar a unos indios jóvenes, les pusieron frenos de caballo en la boca y cormas (a manera de cepos) para limitar su movilidad. Además de otros castigos, les negaron la comida, razón por la que se vieron obligados a comer tierra. Cuando murieron, los enterraron entre los guayabos cercanos al trapiche. ${ }^{51}$ En este último caso, se trató de una forma de relación con los indios por medio de la encomienda, en la que se les rebajaba su condición para tratarlos como a animales. ${ }^{52}$ En todas estas acciones de explotación se encuentra subyacente la idea de que los encomenderos podían ejercer un dominio absoluto sobre los indios, más allá de las regulaciones de los oficiales reales.

Estos actos de abuso y crueldad pueden ser sumamente llamativos, así como los accidentes laborales. Sin embargo, no se puede perder de vista que la situación en los trapiches parecía, según la documentación consultada, poco conflictiva en sí misma, más allá de los aspectos que tenían que ver con la limitación de la actividad agrícola de los indígenas - que reducían su capacidad de abastecerse para el resto del año- y los incidentes cotidianos que seguramente se presentaban. Por lo tanto, resulta más llamativo, por su complejidad, la forma en que se adaptaban las normativas de la corona a las aspiraciones de los encomenderos. Ya vimos anteriormente cómo algunos indios pagaban parte o todo su tributo por medio de la conmutación, de una manera poco ortodoxa, en la que se negociaba entre las partes involucradas, incluso teniendo en cuenta el pago de la parte del rey y del corregidor. En algunos pueblos, el mismo corregidor concertaba el trabajo de los indígenas en los trapiches, como era el caso de Chicamocha, Sunuba y Pacho. ${ }^{53}$ Desafortunadamente, no se cuenta con los 
testimonios de los corregidores en los que explicaran por qué concertaron indios para trabajar en los trapiches, a pesar de que la Corona lo había prohibido explícita y repetidamente. Tal vez siguieron la misma premisa del corregidor de Tunja Juan Ochoa de Unda Jáuregui, quien a comienzos del siglo XVII solicitó que se permitiera el trabajo de los indios en los trapiches, por la necesidad de productos dulces, pero los corregidores de indios subsiguientes optaron por concertar a los indios sin suplicar nada al rey. Es decir, más que una negociación con la Corona, se realizó una modificación local de la ley, para beneficiar a los encomenderos, con los que era probable que los corregidores tuvieran vínculos. ${ }^{54}$

La dulzura de la vida

Hasta ahora, el problema se ha enfocado desde la perspectiva de los indios trabajadores, tanto desde las obligaciones que imponían los encomenderos, como desde las estrategias y mecanismos de adaptación que tenían los propios indígenas. En este apartado se estudiará cómo los indígenas se apropiaban de las posibilidades del trapiche social y económicamente.

Si bien los trapiches podían ser espacios sombríos de trabajo, algunos de ellos se convirtieron en lugares de socialización, especialmente al final de las jornadas laborales o cuando los indígenas podían darse un respiro entre actividades. Llegaron a serlo por dos factores. Por un lado, como se constituían comunidades en torno al trapiche, bien por temporadas o de manera definitiva, los grupos tejían sus redes sociales en ese entorno. Por otro lado, porque los parientes podían acercarse a visitarlos en momentos específicos en que sus actividades lo permitieran. Es cierto que otras actividades de los indígenas de encomienda también permitían esto, pero lo que hacía particular la socialización en el trapiche era el consumo de sus productos, especialmente la miel y el guarapo (en este caso, bebida fermentada producida a partir de la caña dulce). Desde la óptica de los españoles, gracias a estos dos productos, los indios estaban contentos y gordos, muestra del bienestar en que vivían. Ambos productos eran tan apetecidos que atraían a indios forasteros, es decir, que no trabajaban en los trapiches. ${ }^{55}$ La miel de caña y el guarapo eran inexistentes en las tradiciones indígenas antes de la llegada de los españoles. Sin embargo, ambos pudieron encontrar espacio en el consumo de los pueblos. Se puede pensar que esta aceptación se dio porque los humanos, en términos generales, tienen preferencia por los productos dulces. ${ }^{56} \mathrm{~A}$ pesar de que esto puede dar un marco de referencia general, propongo pensar que esta aceptación fue exitosa y se convirtió en un aspecto central de la socialización por dos aspectos: por un lado, porque existió un proceso de homologación de la miel de caña por la miel de abejas. Es claro que ambas mieles tienen un sabor diferente. Sin embargo, morfológicamente, ambas pueden cumplir las mismas funciones en la dieta y por eso era frecuente que los que trabajaban en el trapiche señalaban con satisfacción que se les pagara con botijas de miel. Por otro lado, el guarapo, al
54. En 1610, las autoridades de Tunja aceptaban en un informe a la Corona que en los trapiches trabajaban los indígenas, según ellos por la falta de jornaleros y de negros. Trataban de justificarlo por esta ausencia y por el poco trabajo que representaba para los indios. "Descripción de la ciudad de Tunja, sacada de las informaciones hechas por la Justicia de aquella ciudad en 30 de mayo de 1610" (p. 427)

55. AGN, Colonia, Visitas de Boyacá, t. 15, d. 3. 256r.

56. Armelagos (1996, p. 111). 
57. AGN, Colonia, Visitas de Boyacá, tomo 8 , d. 2, f. $321 \mathrm{v}$

58. AGI, Santa Fe, 61, n. 84, f. $1 \mathrm{r}$. ser una bebida fermentada, podía ocupar el mismo lugar que tenía la chicha (bebida fermentada, principalmente de maíz, pero también de raíces o frutas). Usualmente los indígenas bebían chicha todo el tiempo, porque era un pan líquido que los alimentaba. Para las fiestas, hacían una más fermentada, que los embriagara más. Seguramente con el guarapo se daba un proceso similar: debía de haber uno con poca o ninguna fermentación, para refrescar, y otro realmente fermentado, para embriagar los sentidos. En las fiestas tradicionales indígenas, la chicha era el componente aglutinador por excelencia; en torno a su consumo, se hacían los cantos, se solucionaban los problemas y se reforzaban los lazos sociales. En el trapiche, e incluso por fuera de él, el guarapo fermentado parece haber ocupado este puesto, aunque no de manera absoluta, porque alternaban - combinaban su consumo con el de la chicha, sin que nadie pareciera tener mucho problema al respecto. ${ }^{57}$

Al cambiar una bebida fermentada por otra, o bien complementar una con otra, se podría pensar que, para las comunidades indígenas, la chicha en sí misma no era tan importante como la sensación embriagante. Sin embargo, esto solo era un prejuicio, que incluso existía en el periodo colonial, que se expresaba al señalar a los indios como una "nacion destemplada en el uso de todos géneros de bebidas". ${ }^{58}$ Es claro que el efecto embriagante tenía importancia, porque de lo contrario la fiesta adquiría un sentido diferente; pero lo realmente importante era la posibilidad de celebrar juntos, como grupo, la abundancia del producto dietético central: el maíz. De alguna manera, la chicha simbolizaba eso, porque tenía un fuerte componente comunitario: en comunidad se cultivaba y cuidaba este grano, y así mismo se preparaba la bebida. Aunque este cereal americano seguía ocupando un lugar fundamental en la vida de los indígenas, muchos de los que estaban en el trapiche ya no lo podían conseguir como antes, por la limitación de tiempo para las actividades agrícolas. No implica esto que necesariamente dejaran de cultivar maíz, pero no en las mismas proporciones que antes. Por lo tanto, la posibilidad de dedicar una parte de este para celebrar era más complicado que en el pasado. Por el contrario, como comenzaba a haber abundancia de caña, podían destinar parte al guarapo y así suplir la chicha utilizada en las celebraciones, mas no la de consumo cotidiano.

Si la semejanza de los productos permitió establecer una línea de continuidad entre ambos fue porque tenía sentido en un marco de consumo específico: el festivo comunitario. Un elemento nuevo puede remplazar al antiguo cumpliendo la misma función, porque la estructura le permite adquirir su papel como elemento vinculante. Sin embargo, la introducción de este nuevo producto, el guarapo, terminó alterando la estructura de consumo de bebidas embriagantes en sí misma, porque poco a poco fue perdiendo el sentido comunitario: no todos trabajaban por igual en la producción del guarapo y no todos estaban tan cerca del trapiche como para reunirse allí. Progresivamente, la fiesta perdió la vinculación con la celebración agrícola para convertirse en un consumo relacionado con la 
producción en el trapiche y, si se quiere, individualizado, que ya no necesitaba de los compañeros para consumirse.

La otra forma de apropiación se dio al adoptar el trabajo en el trapiche como granjería propia; es decir, cuando los indígenas se volvían propietarios del entramado azucarero y vendían los productos en beneficio propio. No es sorprendente que en la mayor parte de los casos se trate de trapiches de rueda - manuales, de producción muy limitada. Tal vez lo sorprendente es que la mayoría se encontrara al norte de la gobernación de Popayán, en términos de la minas de Quiebralomo y Supía, así como de la ciudad de Ancerma, a finales de la década de 1620.59 Por el tamaño y la capacidad, se limitaban a producir botijas de miel, conservas de frutas y guarapo. En los trapiches vistos anteriormente, se sabía que las conservas eran de calabacete, diacitron, guayaba, limón, naranja, piña y turrón. 60 En los de los indígenas, se repiten, pero es un poco menos diverso, porque solo hacían de calabazas de castilla, cidra, limones y naranjas. Llevaban los productos a vender a los vecinos de la ciudad, pero sobre todo a los mineros, especialmente los negros, que compraban estos dulces y embriagantes que daban sabor a sus vidas.

¿Por qué se dio en esta región la presencia de estos trapiches indígenas de ruedas? Tal vez la respuesta esté vinculada a la densidad demográfica de los pueblos indígenas (relativamente baja), que no permitió a los encomenderos de la zona establecer bastantes trapiches de tamaño medio, y por esto se popularizó el de rueda o manual. Asismismo, los mercados a los que se podían llevar los productos tenían cierto movimiento, pero no eran grandes centros que hicieran rentable comprar esclavos con miras a tener un trapiche -o incluso un ingenio - que produjera regularmente. ${ }^{61}$ Por lo tanto, este tipo de propiedad pequeña, con un margen de ganancia rentable, se ajustaba bien al trabajo artesanal indígena; además, no implicaba una inversión muy alta y era un modelo simple de imitar y de reparar.

En otras partes del Nuevo Reino no se encuentran muchos indígenas dueños de trapiches de mulas o caballos. Tal vez la consulta de documentos notariales permita tener una visión más completa. En la documentación de las visitas solo se encuentran dos caciques con trapiches en la zona de Vélez. Según los testimonios, los comenzaron a tener a mediados de la década de 1660. En uno de ellos, don Bartolomé, cacique de Pua, señaló que lo trabajaba con su familia y con algunos hombres blancos que contrataba. Por su parte, el otro, don Marcos, cacique de Charalá, apuntó que también lo trabajaba con su familia y en compañía de la cofradía de Nuestra Señora del Rosario. ${ }^{62}$ En ambos casos, se trataba de una producción modesta que, amparada en un nucleo familiar productivo y en algunas personas ajenas a este grupo, permitía garantizar el sustento o, por lo menos, una entrada adicional a estos caciques. Es llamativo que ninguno de los dos haya mencionado a la comunidad de la que eran caciques como colaboradora, ni siquiera en el cultivo. Da la impresión de que, en esta segunda parte del siglo $X V I I$, las lógicas de trabajo son de tipo familiar, alquilado o asociativo (por cuenta
59. AGN, Colonia, Visitas de Cauca, t. 2 , d. 2 , f. 295 r; t. 3 , d. 3 , f. 251 ; t. 6 , d. 2 , f. 374 r.

60. "Descripción de la ciudad de Tunja, sacada de las informaciones hechas por la Justicia de aquella ciudad en 30 de mayo de 1610" (p. 427).

61. Es probable que hubiera de estos trapiches en otras partes de la gobernación de Popayán; el problema es que las visitas de la parte sur de la gobernación las ejecutaban los oidores de la Audiencia de Quito y, por lo tanto, no se encuentran en el Archivo General de la Nación de Colombia. Quizás al consultar en archivos de Popayán y Quito aparezca más información de este tipo.

62. AGN, Colonia, Visitas de Boyacá, t. 1, d. 4, ff. $337 v$ y $344 v$. 
de la cofradía), en tanto que el trabajo comunitario del pueblo parecía haber perdido vigencia en esa zona.

\section{Conclusiones}

El trabajo de los indígenas en los trapiches implicó, además de contravenir ordenanzas de la Corona, un proceso de aprendizaje y adaptación a esas nuevas obligaciones a que se veían abocados. El adiestramiento en prácticas específicas del cultivo, corte y transformación de la caña fue un proceso relativamente rápido para los indígenas. Por lo menos para los que trabajaron en los trapiches, su proceso de entrenamiento no implicó la parte más compleja y valorada de la transformación, que era refinar el azúcar.

La adaptación obligó a los indígenas acomodarse a los nuevos modelos de producción dentro de los esquemas tradicionales de trabajo que tenían. Así se puede citar el cultivo de maíz entre las cañas, y la compañía de los hijos y mujeres para hacer diversas actividades. Se trataba del uso de la familia como unidad básica de producción.

De manera progresiva, estos aprendizajes y adaptaciones fueron transformando la vida indígena en los trapiches, por lo menos en los casos en que el trapiche demandaba mayor presencia de los trabajadores. Una muestra de esto fue lo que se puede denominar el proceso de individuación, tanto por lo que tiene que ver con el sujeto, como con la familia, con respecto a la comunidad a la que pertenecían. Si bien no se dio en todos los casos, en muchos se puede encontrar que el trabajo en el trapiche restringía los lazos con el pueblo y los fortalecía con unidades más pequeñas. Esto puede sonar paradóiico, dado que se acaba de apuntar que la familia era tradicionalmente la unidad básica de trabajo. Sin embargo, el trapiche sacó a la familia de la comunidad amplia, rompiendo los lazos que la recorrían.

Estos cambios se dieron acompañados de muchos otros que alteraron los modelos básicos de vida indígena, en parte porque la Corona buscó transformarla por medio de la introducción de unos patrones de comportamiento claramente cristianos que involucraban, entre otras cosas, el cultivo de productos específicos (trigo), cría de animales (gallinas y ganados), el uso de prendas, así como de ceremonias propias del catolicismo. Lo interesante del trabajo en los trapiches es que introducía los cambios hacia ese modelo, pero en contravía de la Corona.

Más que dar cuenta de la situación laboral de los indígenas en una región específica este artículo permite entender cómo la producción azucarera a una escala modesta suplía regionalmente el abasto de dulce, conectaba económicamente la región y creaba un mercado en el que participaban diferentes actores. Si bien estos trapiches no eran capaces de vincular a la región con mercados externos y con una economía global, su presencia y su producción 
incidían en la mundialización de las costumbres y la transformación de patrones de consumo. Ser una región periférica con respecto a las grandes zonas productivas de azúcar no implicaba que los efectos transformadores del dulce - tanto desde el cultivo de la caña hasta el consumo de los productos - no impactaran en la vida de los grupos aborigenes.

En los trapiches no hubo la inversión que existía en los ingenios, en donde primaba la mano de obra africana; más bien eran modestas empresas, en las que para el encomendero representaba unos reditos importantes, en tanto podían utilizar la mano de obra indígena como parte de una alternativa económica complementaria. Una actividad que era tan importante para la región, que motivó a los corregidores a tergiversar la ley para suplir "necesidades" locales. En algunos casos, debieron disimular para dejar que los encomenderos usaran a los indígenas en los trapiches, pero en otros dieron un aire de legalidad al asunto, otorgando cartas de concierto. Entre la legalidad de la Corona y la aplicación de las leyes, los poderes locales buscaron encontrar un espacio intermedio, que no alterara el panorama económico. 


\section{REFERENCIAS}

\section{FUENTES MANUSCRITAS}

Archivo General de la Nación, Bogotá (AGN) - Sección Colonia

Visitas de Antioquia

Visitas de Boyacá

Visitas de Cauca

Visitas de Cundinamarca

Visitas de Santander

Archivo General de Indias, Sevilla (AGI)

Patronato

Quito

Santa Fe

\section{FUENTES IMPRESAS}

CEY, Galeotto. Viaje y descripción de las Indias, 1539-1553. Edición de José Rafael Lovera. Caracas: Biblioteca Nacional, 1994.

COVARRUBIAS HOROZCO, Sebastián. Tesoro de la lengua castellana o española. Madrid: Luis Sánchez, 1611.

KONETZKE, Richard. Colección de documentos para la bistoria de la formación social de Hispanoamerica, 1493-1810. Volumen II, segundo tomo (1660-1690). Madrid: Centro Superior de Investigaciones Científicas, 1958.

RECOPILACIÓN de leyes de los reynos de las Indias. Tomo segundo. Madrid: [s.n.], 1791. Torres de Mendoza, Luis. Colección de documentos inéditos relativos al descubrimiento, conquista y organización de las antiguas posesiones españolas en América y Oceanía, sacados de los archivos del reino y muy especialmente del de Indias por don Luis. Madrid: 1964, Vaduz. 
XIMÉNEZ, Francisco. Quatro libros de la naturaleza, y virtudes de las plantas, y animales que están recevidos en el uso de medicina en la Nueva España, y la método, y corrección, y preparación, que para administrallas se requiere con lo que el doctor Francisco Hernandes escrivio en lengua latina. [...] Traduzido y aumentados muchos simples, y compuestos y otros muchos secretos curativo, por Fr. Francisco Ximenez, hijo del convento de S. Domingo de Mexico, natural de la villa de Luna del reyno de Aragón.[...] Mexico: en casa de la viuda de Diego López Davalos, 1615.

\section{LIBROS Y ARTÍCULOS}

ARMELAGOS, George. Cultura y contacto: el choque de dos cocinas mundiales. In: LONG, Janet (coord). Conquista y comida. Consecuencias del encuentro de dos mundos. México: Universidad Nacional Autónoma de México, 1996, p. 105-129.

BARRET, Ward. The Sugar Hacienda of the Marqueses del Valle. Minneapolis: University of Minessota Press, 1970.

BONNETT, Diana. Trabajo y condiciones de vida indígena en la Nueva Granada colonial. In: QUIROZ, Enriqueta. BONNETT, Diana (coord.). Condiciones de vida y de trabajo en la América colonial: Legislación, prácticas laborales y sistemas salariales. Bogotá: Universidad de los Andes, 2009, p. 23-43.

COLMENARES, Germán. Historia económica y social de Colombia, 1537-1719. Tomo I. Bogotá: Tercer mundo, 1999.

CROWLEY, John. Sugar Machines: Picturing Industrialized Slavery. American Historical Review, Bloomington, v. 121, n. 2, p. 403-436, Apr. 2016.

EBERT, Christopher. Between Empires: Brazilian Sugar in the Early Atlantic Economy, 15501630. Leiden; Boston: Brill, 2008.

FRAGINALS MORENO, Manuel. El ingenio: Complejo económico social cubano del azúcar. Barcelona: Crítica, 2001.

FUNES MONZOTE, Reinaldo. De bosque a sabana: Azúcar, deforestación y medio ambiente en Cuba: 1492-1926. México: Siglo XXI, 2004.

Plantaciones esclavistas azucareras y transformación ecológica en Cuba. Revista Historia, Heredia, n. 59-60, p. 35-54, 2009.

GAMBOA MENDOZA, Jorge Augusto. El cacicazgo muisca en los años posteriores a la Conquista: del sihipkua al cacique colonial. Bogotá: ICANH, 2010.

GÓMEZ GÓMEZ, Mauricio Alejandro. Del chontal al ladino: La hispanización de los indios de Antioquia según la visita de Francisco de Herrera Campuzano, 1614-1616. Medellín: FCSH Universidad de Antioquia, 2015. 
Indios contra encomenderos en tierra de frontera. Antioquia a inicios del siglo XVII. Trashumante: Revista americana de Historia social, Medellín/México, n. 3, p. 8-26, ene./jun. 2014.

HUETZ DE LEMPS, Alain. Boissons coloniales et essor du sucre. In: FLANDRIN, JeanLouis; MONTANARI, Massimo (coord.). Histoire de l'alimentation. Paris: Fayard, 1996, p. 629-641.

MARTÍNEZ MOYA, Arturo. La caña da para todo: Estudio histórico cuantitativo del desarrollo azucarero dominicano (1500-1930). Santo Domingo: Archivo General de la Nación, 2011.

MILLER, Shawn. Fuelwood in Colonial Brazil: The Economic and Social Consequences of Fuel Depletation for the Bahian Recôncavo, 1549-1820. Forest and Conservation History, Durham, n. 38, p. 181-192, 1994.

MINTZ, Sidney. Dulzura y poder. el lugar del azúcar en la historia moderna. México: Siglo XXI, 1996.

ORTíz, Fernando. Contrapunteo cubano del tabaco y el azúcar. La Habana: Pensamiento Cubano, 1983.

RAMíREZ MÉNDEZ, Luis Alberto. Las haciendas cañeras en el sur del lago de Maracaibo Venezuela (siglos XVI-XVII). Revista de Indias, Madrid, v. LXXIV, n. 260, p. 9-34, 2014.

RODRÍGUEZ MOREL, Genaro. The Sugar Economy of Española in the Sixteenth Century. In: SCHWARTZ, Stuart (ed.). Tropical Babylons: Sugar and Making of the Atlantic World, 14501680. Chapel Hill; London: The University of North Carolina Press, 2004, p. 85-114.

SALDARRIAGA, Gregorio. Alimentación e identidades en el Nuevo Reino de Granada, siglos XVI y XVII. Bogotá: Universidad del Rosario, 2011.

SÁNCHEZ MEJÍA, Hugues. Haciendas de trapiche, hatos, hatillos y "rozas": el mundo rural en la Gobernación de Santa Marta (1700-1810). Historia Caribe, Barranquilla, v. XI, n. 28, p. 241274, ene./jun. 2016.

SCHWARTZ, Stuart. Introduction. In: (ed.). Tropical Babylons: Sugar and Making of the Atlantic World, 1450-1680. Chapel Hill; London: The University of North Carolina Press, 2004, p. 1-24.

TADMAN, Michael. The Demographic Cost of Sugar: Debates on Slaves Societies and Natural Increase in the Americas. The American Historical Review, Bloomington, v. 105, n. 5, p. 15341575, Dec. 2000.

VANEGAS DURÁN, Claudia Marcela. Los pueblos de indios y el abasto de leña de las ciudades de Tunja y Santafé, siglos XVI y XVII. Fronteras de la Historia, Bogotá, v. 20, n. 2, p. 92-122, 2015.

VARGAS LESMES, Julián. La sociedad de Santa Fe Colonial. Bogotá: Cinep, 1990.

Artigo apresentado em 31/10/2016. Aprovado em 23/02/2017. 